\title{
Metaplasia mieloide do baço na Ancilostomose (")
}

\author{
por \\ W. O. CRUZ \\ (Com as estampas LVI-LVIII)
}

Os conhecimentos de embriologia ensinam que a hematopoiese no embrião realiza-se na sua fase inicial, exclusivamente no figado e no baço. Com o desenvolvimento do organismo a medula dos ossos adquire a propriedade de formar os elementos figurados do sangue, sendo este orgão responsavel, na vida extra-uterina, pela produção da maioria das celulas hematicas.

Ehrlich foi o primeiro a descrever no adulto uma regressão funcional de determinados tecidos ao estado embrionario, verificando, no baço de um caso mortal de anemia perniciosa, o aparecimento de celulas ancestrais dos globulos vermelhos $\mathrm{e}$ brancos. A isto denominou metaplasia mieloide.

Dominici (1) conseguiu observar no coelho a metaplasia mieloide no baço e figado durante a prenhez, anemiando esse animal por hemorragias sucessivas, e nele inoculando bacilo tifico, ou ainda determinando uma tuberculose experimental.

Meyer e Heineke (2) observaram a metaplasia mieloide no homem, em dois casos de septicemia, sete casos de anemia perniciosa, em um caso de anemia associada a uma cardiopatia e na leucemia mieloide.

Morris (3), Lang (4) e Guccione (5), experimentando em coelhos ou cobaias, obtiveram os mesmos resultados que Dominici, injetando carmin, pirodina, vacina de $B$. coli, diversos corantes vitais e saponina.

A metaplasia mieloide foi observada tambem em numerosas doencas de origem infecciosa (escarlatina, erisipela, septicemia, meningite, difteria, sifilis congenita, tifo exantematico), de origem parasitaria (kalaazar, disenteria amebiana), em doenças de virus (vacina e variola). Reaentemente Cattaneo (6) obteve experimentalmente a metaplasia, inoculando coelhos com virus vacinico. Domarus (7) e Jaffé (8) a verificaram em anemias experimentais produzidas em cães jovens e em ratos, pelo pirogalol, fenilidrazina e outras substancias anemiantes.

(") Recebido para publicação a 10 de Maio de 1934. 
É na leucemia mieloide que se verifica maior regressão ao estado fetal, pois aí encontra-se o baço completamente transformado em tecido hematopoietico. Na anemia pseudo-leucemica das crianças verificase a metaplasia não só no baço e figado como tambem no pancreas; rins e ganglios linfaticos.

Nos tratados de Anatomia Patologica de Mac Callum, Aschoff, Delafield e Prudden, encontra-se assinalado que a metaplasia mieloide se constata no homem, não só nas doenças já citadas como tambem nas anemias secundarias graves.

É ainda obscura a significação do aparecimento desta metaplasia mieloide em doenças infecciosas, parasitarias, de virus, ou quaisquer outras que não venham acompanhadas de anemia. Nesta ultima, ela é geralmente interpretada como um processo compensador, comum a todos os casos onde é premente a necessidade de uma regeneração sanguinea.

A interpretação hematologica da metaplasia mieloide é dada cabalmente na concepção de Ferrata (9) sobre a genese das celulas sanguineas. Para este autor, os eritrocitos, os granulocitos e as plaquetas derivam, por diferenciações sucessivas, de um mesmo tipo de celula, a que êle chamou hemocitoblasto mieloide. Os linfocitos se derivam de uma celula analoga denominada hemocitoblasto linfoide. Os monocitos do sangue (pela fase intermediaria de monoblasto), os hematocitoblastos mieloide e linfoide derivam de uma celula ancestral comum, denominada hemoistioblasto.

Sôbre a denominação de hemoistioblasto compreende Ferrata um grupo de celulas bem determinadas do sistema reticulo-endotelial. No adulto êste grupo é formado pelas celulas do tecido reticular periferico, pelas celulas do reticulo dos orgãos hemolinfopoieticos, pelas celulas marginais e finalmente pelos clasmatocitos. Tais celulas que se encontram nos mais diferentes orgãos da economia, conservam o caracter embrionario de indiferenciação. Assim, pódem elas evoluir tanto para a celula madura do tecido conjuntivo, para os monocitos do sangue, para muitos dos elementos macrofagos de tecidos inflamatorios, como tambem para os elementos das series branca e vermelha.

Em uma anemia grave, ou em uma reação granulocitica intensa, o hemoistioblasto, evolue para hemocitoblasto mieloide para finalmente produzir hematias e leucocitos. Compreende-se então que basta haver emm um orgão qualquer uma das celulas do sistema reticulo-endotelial acima citadas, para se verificar aí, em condições de forte solicitação, o aparecimento de celulas medulares, ou seja, da metaplasia mieloide.

A frequencia da metaplasia mieloide nas anemias secundarias gra- 
ves, fazia crêr que na anemia atribuida ao Ancilostomo e ao Necator, tambem se verificasse o mesmo fato.

A nosso conhecimento nesta helmintose ainda não foi dado á publicidade qualquer constatação no assunto, e daí a publicação da presente nota, que além de confirmar as aquisições já obtidas em casos possivielmente semelhantes, vem trazer mais uma documentação para a excessiva hiperplasia dos elementos da seria vermelha, e uma confirmação sôbre a grande preponderancia dos normoblastos, por nós verificada anteriormente na medula ossea desta doença (10).

\section{Observações}

O material foi retirado de casos puros de ancilostomose, nos quais já haviamos estudado a medula ossea. O diagnostico anatomo-patologico, as observações que interessam mais ao assunto, como a descrição e documentação fotografica do aspeto deste orgão, se encontram em nosso trabalho anterior (10), e aqui estes dados serão omitidos.

Os córtes foram corados pela hematoxilina e eosina, ou pelo metodo aconselhado por Ellermann (Eosina-Giemsa).

O exame microscopico do baço e figado, aqui apresentados, de modo algum devem ser tomados como um estudo histopatologico destes orgãos, pois que foram tão sómente pesquizadas com cuidado as celulas hemoformadoras.

\section{OBSERVAÇÃO 1:}

Aut. n. ${ }^{\circ}$ 5411, Olga, 23 anos.

Exame microscopico do baço: Foliculos linfoides bem individualisados. Não ha congestão, esclerose ou pigmentos. Plasmazellen pouco frequentes. Na polpa esplenica, presenca de numerosos normoblastos com nucleo picnotico (Fig. 1) de megacariocitos e de mielocitos eosinofilos.

Exame microscopico do figado: Infiltração gordurosa extensa. Presença de pigmento (provavelmente pigmento biliar). Não foram vistos elementos imaturos da série vermelha.

\section{OBSERVAÇÃO 2 :}

Aut. 6081, João, 32 anos.

Peso do baço: 110 grs.

Exame microscopico do baç: Foliculos linfoides sem qualquer anomalia. Polpa vermelha com numerosissimas celulas. Presença de numerosos normoblastos (Fig. 2) de plasmazellen e macroplasmazellen e de megacariocitos. Numerosos leucocitos eosinofilos. Ausencia de pigmento. 
Exame microscopico do figado: Infiltração gordurosa muito exbensa. Desaparecimento quasi completo do parenquima nobre. Não ha pigmentação. Não foram observados elementos imaturos da série vermelha.

\section{OBSERVAÇÃO 3 :}

Aut. 1817, João P., 25 anos.

Peso do baço: 195 grs.

Exame microscopico do baç: Foliculos linfoides de número e aspeto normal. Na polpa esplenica encontram-se numerosos leucocitos neutrofilos e eosinofilos, como tambem numerosos normoblastos (Fig. 3). Ausencia de pigmentação.

Exame microscopico do figado: Infilttração gordurosa. Ausencia de pigmentação. Não foram vistos elementos imaturos da série vermelha.

\section{OBSERVAÇÃO 4:}

Aut. 1989, Amelia, 20 anos presumiveis.

Peso do baço: 175 grs.

Exame microscopico do baço: Nos foliculos linfoides nota-se proliferação nitida dos linfoblastos. Esclerose. Polpa esplenica com poucas celulas, entre as quais nota-se numerosos normoblastos (Fig. 4). Degeneração hialina das arteriolas peniciladas. Presença de pigmento.

Exame do figado: Infiltração gordurosa. Não ha pigmentação nem celulas imaturas da série vermelha.

OBSERVAÇÃO 5:

Aut. 6136, Antonio, 59 anos.

Peso do baço: 170 grs.

Exame microscopico do baço: Aspeto normal dos foliculos linfoides. Esclerose. Na polpa esplenica numerosos mielocitos eosinofilos, plasmazellen, e presença de megacariocitos e normoblastos (Fig. 5). Ausencia de pigmento.

Exame do figado: Infiltração gordurosa extensa. Esclerose. Ha sómente pequenas ilhotas de parenquima hepatico. Não foram observadas celulas vermelhas imaturas.

OBSERVAÇÃO 6:

Aut. 5747, Cecilia, 22 anos.

Peso do baço: 250 grs.

Exame microscopico do baco: Aspeto normal dos foliculos linfoides. 
Ligeira esclerose. Polpa esplenica rica em celulas. Aí observam-se numerosissimos plasmazellen e macroplasmazellen. Presença de raros normoblastos (Fig. 6). Presença de pigmento.

Exame do figado: Infiltração gordurosa. Congestão passiva. Pigmento, provavelmente de origem biliar. Não são vistos elementos imaturos da série vermelha.

OBSERVAÇÃO 7 :

Aut. 6118, Nelson, 14 anos.

Peso do baço: 130 grs.

Exame microscopico do baç: Aspeto normal dos foliculos linfoides. Polpa esplenica rica em celulas. Presença de numerosos normoblastos (Fig. 7) e plasmazellen. Ausencia de pigmento.

OBSERVAÇÃO 8:

Aut. 1257, Carlos, 64 anos.

Exame microscopico do baco: Aspeto normal dos foliculos linfoides. Esclerose. Na polpa esplenica notam-se numerosos plasmazellen. Presença de pigmento. Não se observou, com certeza, a presença de normoblastos.

Exame do figado: Infiltração gordurosa discreta. Esclerose. Pigmentação, provavelmente de origem biliar. Ausencia de elementos imaturos da série vermelha.

\section{OBSERVAÇÃO 9 :}

Aut. 1638, Salvino, 52 anos.

Exame microscopico do baco: Foliculos linfoides de aspeto normal. Esclerose. Na polpa esplenica observa-se aspeto de esplenite aguda. Congestão intensa, numerosos leucocitos neutrofilos nos seios venosos. Ausencia de pigmentação. Numerosos plasmazellen. Presença de megacariocitos.

Exame do figado: Infiltração gordurosa. Esclerose. Infiltração celular no espaço porta e em torno dos vasos de maior calibre. Não ha pigmentação. Ausencia de elementos imaturos da série vermelha.

OBSERVAÇÃO 10 :

Aut. 1777, Luiz, 60 anos.

Peso do baço: 210 grs.

Exame microscopico do baço: Esclerose. Aspeto normal dos foliculos linfoides. Na polpa esplenica nota-se o aspeto da esplenite aguda. Numerosos leucocitos neutrofilos nos seios venosos. Congestão intensa. 
Ausencia de pigmentação. Numerosos leucocitos eosinofilos e plasmazellen. Não é evidente a presença de normoblastos.

Exame do figado: Esclerose. Infiltração gordurosa discreta. Ausencia de pigmentação. Infiltração celular em torno dos vasos. Não ha elementos imaturos da série vermelha.

\section{PESO DO BAÇO EM CASOS DE ANCILOSTOMOSE}

(Dados retirados da Seção de Anatomia-Patologica do Instituto Oswaldo Cruz).

\begin{tabular}{|c|c|c|c|c|}
\hline Numero da autopsia & Edade (anos) & $\begin{array}{c}\text { Peso do baço } \\
\text { (grs.) }\end{array}$ & Peso médio (grs.) & $\begin{array}{c}\text { Peso do baço no nor } \\
\text { mal nas respectivas ida. } \\
\text { des (grs.) }\end{array}$ \\
\hline 5426 & 3 & 60 & & \\
\hline 4145 & 3 & 110 & & \\
\hline 4160 & 4 & 70 & 63 & 50 \\
\hline 4156 & 4 & 45 & & \\
\hline 5107 & 4 & 30 & & \\
\hline 3094 & 6 & 100 & & \\
\hline 4016 & 7 & 135 & & \\
\hline 5088 & 8 & 90 & & \\
\hline 4265 & 9 & 70 & 95 & 60 \\
\hline 4297 & 9 & 70 & & \\
\hline 5103 & 9 & 105 & & \\
\hline 2531 & 12 & 150 & & \\
\hline 2486 & 12 & 75 & 118 & 80 \\
\hline 6118 & 14 & 130 & & \\
\hline 1989 & 20 & 175 & & \\
\hline 5032 & 22 & 150 & the & \\
\hline 5747 & 22 & 250 & & \\
\hline 1817 & 25 & 195 & & \\
\hline 5056 & 27 & 140 & 174 & 170 \\
\hline 2457 & 28 & 165 & & \\
\hline 6081 & 32 & 110 & $x+$ blige & \\
\hline 6136 & 59 & 170 & & \\
\hline 1777 & 60 & 210 & & \\
\hline
\end{tabular}




\section{INTERPRETAÇÃO E DISCUSSÃO.}

A unica verificação uniforme foi a da ausencia de metaplasia mieloide no figado. No baço, encontramos proliferação do tecido conjuntivo, . $\mathrm{m}$ individuos idosos, em quatro casos (Obs. 5, 8, 9 e 10); presença de pigmentação em tres casos (Obs. 4, 6 e 8), dos quais um havia tomado ferro um dias antes da morte e os outros dois são duvidosos a respeito da ingestão da mesma substancia. Na maioria dos casos, observou-se uma completa ausencia de pigmentos na pôlpa esplenica, o que vem confirmar o que já se sabia a respeito da pouca destruição sanguinea na anemia ancilostomotica. Com a excepção de dois casos (Obs. 3 e 4), observou-se um aumento numerico, por vezes notavel, dos plasmazellen. A presença de celulas hemocito-formadoras, não encontradas normalmente no baço, foi constatada em diversos casos. Observam-se megacariocitos nas observações 1, 2, 5 e 9; mielocitos eosinofilos numerosos nas observações 1 e 5 , e eritroblastos já avançados em evolução em quasi todos os casos (excepto obs. S, 9 e 10). De modo seguro, não foi nolada em nenhum caso a presença de eritroblastos basofilos ou policromaticos.

Não ha uma opinião formada sôbre as modificações do volume do baço na ancilostomose. Em alguns autores encontram-se referencias a um aumento ligeiro, emquanto que outros afirmlam ser êste orgão de volume normal. Os dados aqui apresentados, retirados de 23 casos de ancilostomose, sem associação com qualquer outra doença, mostram que, em média, o baço de adultos não se acha aumentado em peso. Tal não acontece, porém, em individuos abaixo de 15 anos, nos quais èste orgão encontra-se nitidamente aumentado.

Não nos foi dado examinar o baço de individuos jovens, a não ser em um unico caso, mas acreditamos ser provavel que neles êste orgão apresente sempre uma metaplasia mieloide. O que assim nos faz pensar, está no fato de que sómente em individuos acima de 50 anos não encontramos êste tipo de regeneração. É evidente que se encontrará mais facilmente nas crianças esta regressão ao estado fetal, o que nos sugere para a explicação do aumento do baço nelas observado a existencia de uma proliferação intensa de celulas medulares.

Estas verificações nos orgãos hemoliticopoieticos na ancilostomose, que parecem ser comuns a todas anemias hipocromicas, ferro-sensitivas, têm uma grande significação elucidativa, não só na patogenia destas anemias, como tambelm no processo de regeneração sanguinea com o tratamento. Como a compreensão clara destas relações, provavelmente, abrirá novos caminhos a pesquizas mais detalhadas, daremos a seguir uma vista de conjunto de todos estes fatos. 
Sabemos que os elementos da série vermelha dos orgãos hemopoeticos, no estado normal, não são excitados com a administração exagerada de substancias ativas para eles. Do mesmo modo, a administração na anemia perniciosa dos principios hematopoieticos do figado, ou nas anemias hipocromicas o emprego dos saes de ferro, após a normalização das cifras sanguineas, não causam um exagero na produção de globulos e de hemoglobina. A excitação destes orgãos é devida essencialmente á carencia de substancias, como se póde verificar nas hemorragias agudas, onde a saída do sangue para fóra do organismo produz, no individuo normal, uma forte regeneração hemo-formadora.

Para melhor compreensão dos fatos observados em natureza, quanto a perturbações sanguineas, dever-se-á admitir que os orgãos hemocitopoieticos estejam normalmente sob uma ação frenadora constante de determinadas substancias existentes no organismo. Logo que as quantidades destas substancias diminuem, os orgãos formadores do sangue imediatamente proliferam, e proliferam tanto mais quanto maior a quantidade de substancia eliminada da economia. Tanto maior a hemorragia, tanto maior a regeneração, tanto maior a gravidade de uma anemia de causa carencial, - pelo menos na ancilostomose isto se observa - tambem tanto maior a hiperplasia dos elementos medulares imaturos.

No caso em questão, de uma carencia de ferro, a hiperplasia dos orgãos hemocitopoieticos, parece se processar de maneira especifica em relação ao tipo celular proliferado. Na medula ossea normal ha uma nitida predominancia do normoblasto sôbre as outras celulas da série vermelha. Sabin e Doan (11) verificaram que na do coelho encontram-se normalmente $70 \%$ de granulocitos, $25 \%$ de celulas vermelhas nucleadas e $5 \%$ de outras variedades. Esses autores verificaram mais que entre os elementos da série vermelha, os normoblastos existem na porceintagem de $69 \%$, ou seja, considerando em relação a todas celulas medulares, $17 \%$. Na medula ossea da ancilostomose, quando não é muito intensa a reação eosinofilica medular, ha uma porcentagem de normoblastos nitidamente acime de $50 \%$, tal como se póde verificar facilmente na documentação fotografica de um nosso trabalho anterior $(10)$. Ha, pois, um aumento de $17 \%$ para $50 \%$ ou seja aproximadamente de $30 \%$ em normoblastos, na medula ancilostomotica.

Morfologicamente, o normoblasto, encontrado em tão grande número nos orgãos hemoliticopoieticos dos ancilostomados, é em tudo semelhante ao normoblasto normal. A lesão fundamental da doença parece se processar na fase de evolução seguinte, para a formação da hematia jovem (Reticulocito). Já Witts (12) assinala que provavelmente o ferro é uma substancia indispensavel para o processo de maturação 
normal do normoblasto para eritrocito. Acreditamos que, na verdade, assim seja, e esperamos dar futuramente uma contribuição mais diréta a esta questão.

A normoblastose, acarretada por uma deficiencia de ferro, é um fato de observação constante. No homem, segundo deixa entrever Witts, ela é sempre presente em todas as anemias ferro-sensitivas, e, recentemente, póde-se concluir o mesmo do trabalho de Keith e Miller (13) na anemia nutritiva do rato. Dizem estes autores: "Hematopoietic centers appear in the liver and spleen, while tends to disappear from bone marrow, being replaced by erythroblastic tissue ». Como estes autores não descrevem qualquer anomalia nos tecidos eritroblasticos verificados, acreditamos que os normoblastos dominem em número as outras celulas da série vermelha, tal como se observa no coelho normal.

Já referimos antes, e aqui insistimos, sôbre a significação deste faclo para o metabolismo da hemoglobina. A forte regeneração normoblastica nesta anemia indica, antes de tudo, uma sintese de hemoglobina em quantidade notavel. A carencia de ferro no organismo não parece influir na formação do pigmento sanguineo, mas sim em um processo de oxydação particular ao normoblasto. Está assinalada em outras anemias, e nós constatámos tambem, na ancilostomose, uma eliminação exagerada de acido urico pela urina, no periodo de regeneração sanguinea pela administração de ferro. O processo de maturação do normoblasto nada mais é que o desaparecimento, ou melhor, a transformação do nucleo desta celula. Um dos produtos finais da nucleina é o acido urico, e esta transformação é essencialmente uma oxidação. Esta deficiencia de oxidação acarreta um disturbio no metabolismo da hemoglobina, pois, apezar da proliferação exagerada nos normoblastos, estas celulas permanecem retidas no baco e na medula ossea. A neoformação de hematias na ancilostomose, á medida que progride a anemia, vai-se processando de maneira qualitativamente insuficiente até atingir os caracteres degenerativos que mostram estas celulas, quando observadas na circulação periferica nesta anemia. Disto resulta o aspeto paradoxal, de uma medula ossea rica em eritroblastos com hemoglobina e um sangue com hematias (por vezes em número normal), pobres nesta substancia.

E, na verdade, um fato muito curioso a verificação, mesmo superficial, de uma autopsia de um caso de ancilostomose. De um lado notámos um sangue pobre em pigmento respiratorio, que, por uma deficiencia de oxygenação dos tecidos, acarreta uma degeneração de quasi todos os or- 
gãos, iemquanto que, de outro lado, observamos no baço, mas principalmente dentro dos ossos, êste pigmento aí retido em grande abundancia.

Com estes dados fica perfeitamente compreensivel a grande regeneração sanguinea, observada na ancilostomose após a administração de ferro. Si bem que esta substancia, provavelmente, tambem provoque uma neo-produção de hemoglobina, é essencialmente á liberação normal das celulas eritroblasticas, já carregadas deste pigmento, que se deve a rapida recomposição do sangue, e, assim, a volta ao estado higido, em tempo relativamente tão curto.

\section{SUMARIO E CONCLUSÕES}

Pesquizamos, no figado e baço de dez casos puros de ancilostomose, elementos hemocitopoieticos; verificamos o peso do baço em 23 casos de individuos com idades compreendidas entre 3 e 60 anos; não encontramos, em nenhum caso, celulas hemoformadoras no figado. Em sete casos, encontramos, no baço, elementos da série vermelha em adiantado estado de evolução (eritroblastos ortocromaticos de nucleo picnotico). Em alguns destes casos observamos megacariocitos e numerosos mielocitos eosinofilos. Os tres casos que não apresentavam metaplasia mieloide no baço, eram os de individuos acima de 50 anos de idade. Entretanto, em outro caso de um individuo com 59 anos esta metaplasia foi verificada. Em individuos acima de 20 anos, o peso médio do baço, em nove casos, mostrou-se igual ao peso normal. Em 14 casos, compreendidos entre 3 e 14 anos, o peso deste orgão foi sempre sensivelmente mais elevado que nos normais de idade correspondente.

Estes resultados sugerem a possibilidade de ser a metaplasia mieloide responsavel pelos aumentos de pezo nos baços de individuos jovens, vitimados pela anemia ancilostomica.

A notavel proliferação dos eritroblastos ortocromaticos mostra que o gráo e a rapidez da regeneração sanguinea, após a administração de ferro, são devidos, essencialmente, á grande quantidade de hemoglobina já preformada no baço e na medula ossea dos organismos ancilostomados.

\section{BIBLIOGRAFIA}

1). DOMINICI - Études sur la transformation mieloide. - Comp. Rend. Soc. Biol., 1899, 1900, vols. 1 e 2.

2) MEYER \& HEINEKE - Ueber Blutbildung in Milz und Leber bei schweren Anaemien. - Verhandl. der deutschen path. Ges., 1905, 9, 224.

3) MORRIS, R. - Blood formation in the liver and spleen in experi- 
mental anaemia. - John Hopkins Hosp. Buli., 1907, 18,200 .

4) LANG - Zeitsch. f. mikr. anatom. Forsch., 1926, fol. 4 .

5) GUICCIONE - Arch. di patol. e clin. med., 1926, vol. 5.

6) CATTANEO, L. - Sulle metaplasie mieloidi nelle malattie infettive sperimentali. - Haemat. Arch., 1932, 13, 39.

7) DOMARUS - Ueber Blutbildung in Milz und Leber bei experimentellen Anaemien. - Arch. f. exp. Path. \& Pharm., 1908, 58, 319.

8) JAFFÉ-Die extramedullare Blutbildung bei anaemischen Mäusen. - Beitr. z. Path.-anat. \& Path., 1921, 68, 224.

9) FERRATA - Le Emopatie.

10) CRUZ, W. O. - Da medulla ossea na ancylostomose. - Mem. Inst. Osw. Cruz, 1933, 27, 423.

11) SABIN \& DOAN - Bone-marrow as an organ. - Proc. Soc. Exp. Biol. \& Med., 1927, 25, 121.

12) WITTS, L. J. - The pathology and treatment of anaemia. - The Lancet, 1932, 1, pag. 549.

13) KEITH \& MILLER - The development and functional activities of the albino rat as affected by diets deficient in iron.

- Journ. Agric. Res., 1933, 46, 943.

\section{EXPLICAÇÃO DAS ESTAMPAS LVI-LVIII.}

Todas microfotografias são constituidas por córtes de material retirado de baço. O número das figuras corresponde ao número das observações.

\section{ESTAMPA LVI}

Fig. 1 -Aprox. $2.000 \times$. Vê-se um normoblasto com contorno nuclear e plasmatico bem nitidos.

Fig. 2-Aum. $700 \times$. Observa-se o contorno nuclear de diversos normoblastos.

Fig. 3-Aum. 470. $\times$. Perto de uma trave conjuntiva observam-se numerosos nucleos escuros de normoblastos.

\section{ESTAMPA LVII}

Fig. 4 -Aum. $470 \times$ Normoblastos disseminados, reconheciveis pelo seu nucleo picnotico e de contorno circular nitido.

Fig. 6 -Aum. $700 \times$. Normoblastos disseminados, vendo-se no centro da fotografia uma destas celulas com contorno plasmatico nitido. 


\section{ESTAMPA LVIII}

Fig. 5-Desenho. Imersão, oc. 4, desenhado na altura da platina. Verificam-se facilmente no centro da figura, dois normoblastos tipicos.

Fig. 7 -Desenho. Imersão, oc. K 6, desenhada na altura da platina. Os nucleos homogeneamente escuros pertencem a normoblastos. Nas partes laterais do desenho vêm-se claramente duas destas celulas. 


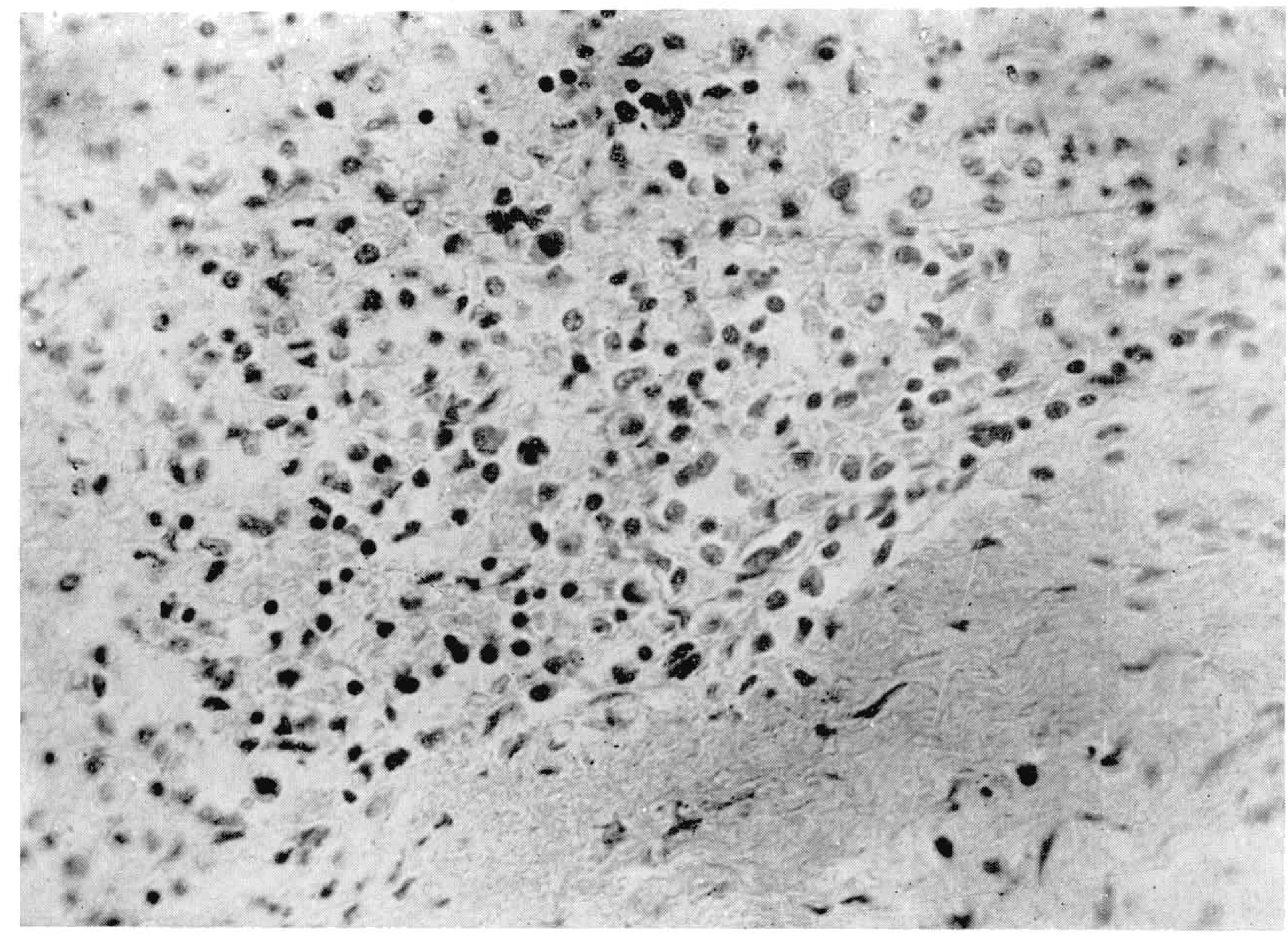

Fig. 3

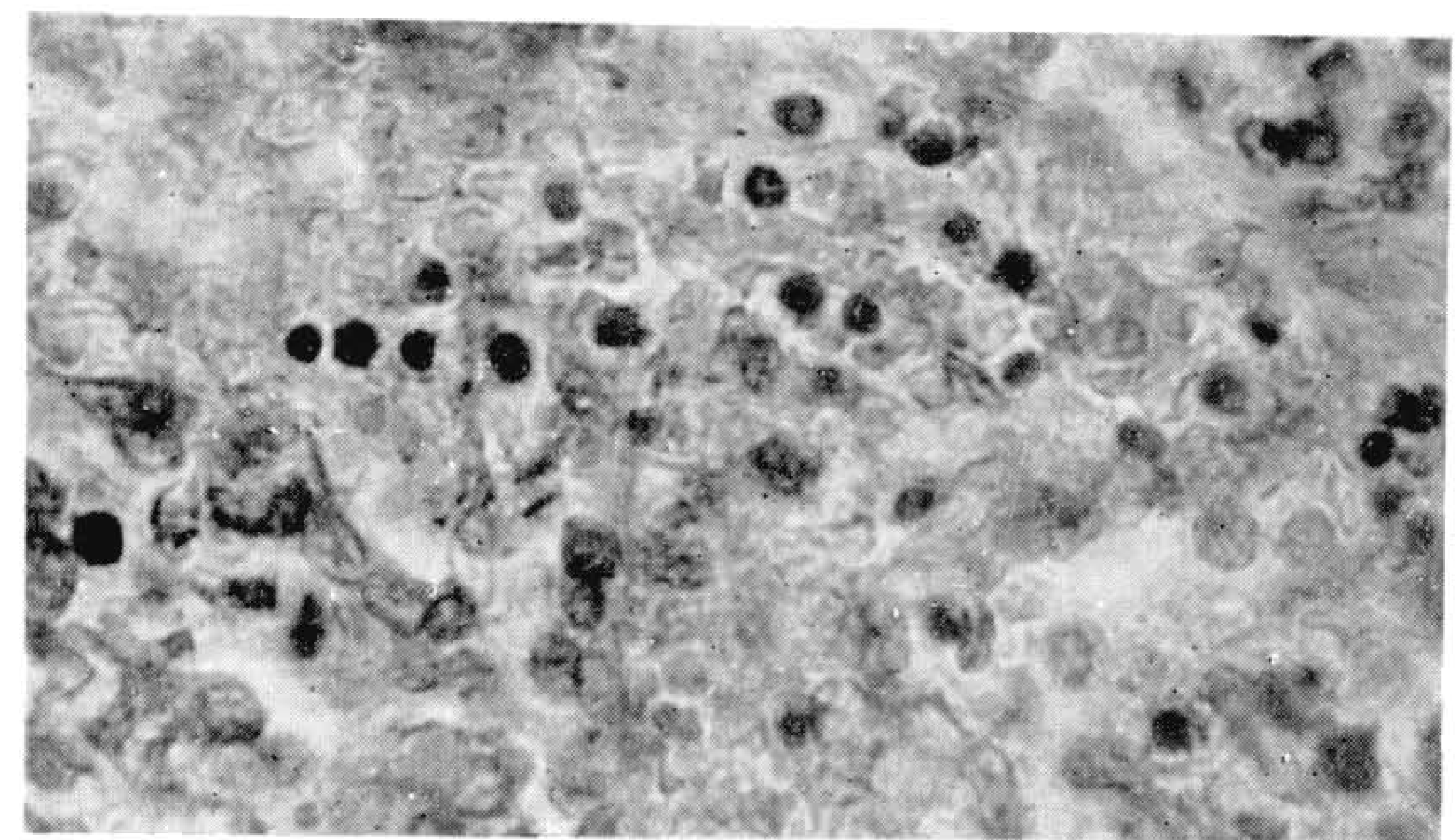

Fig. 2

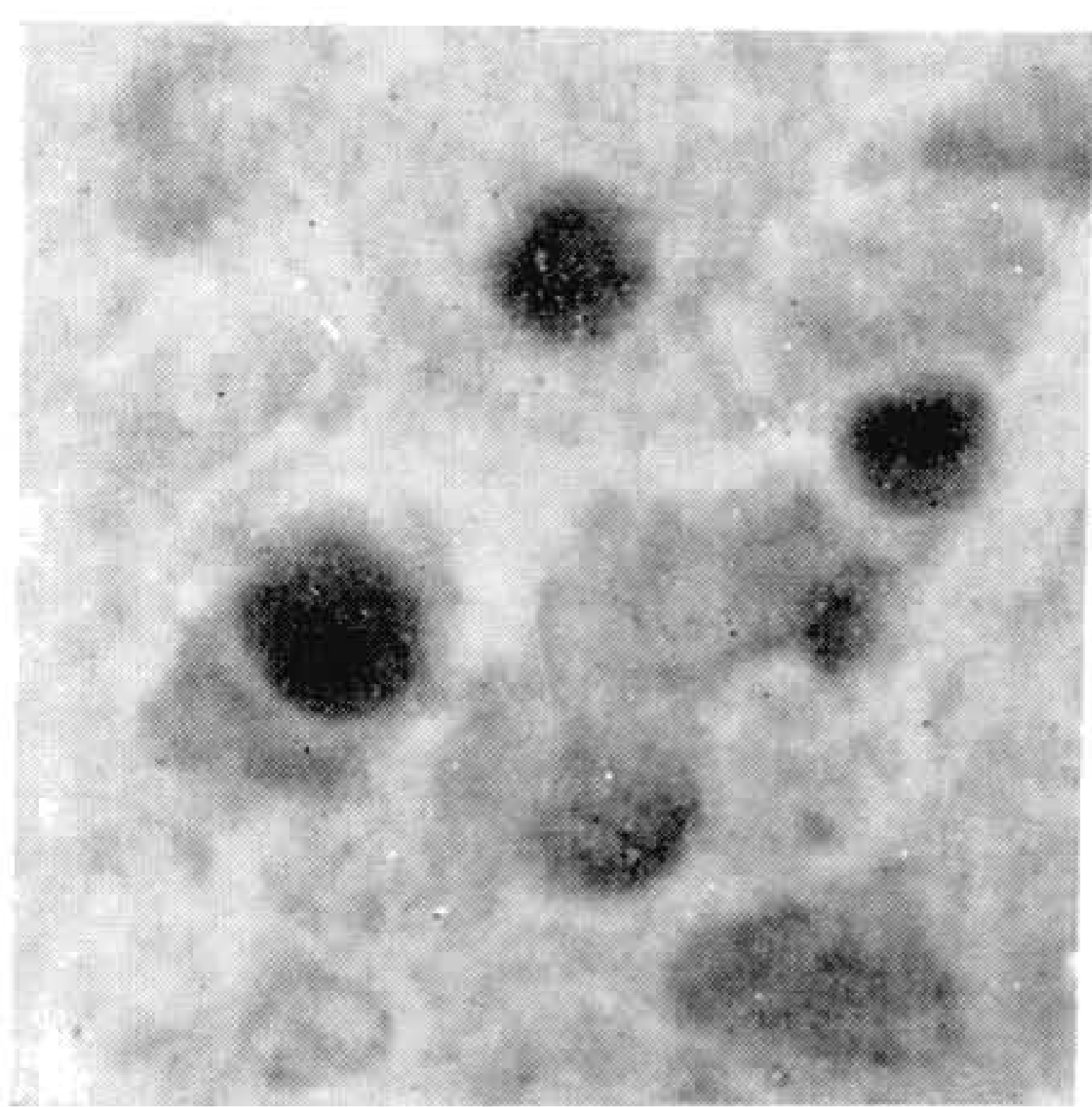

Fig. 1 


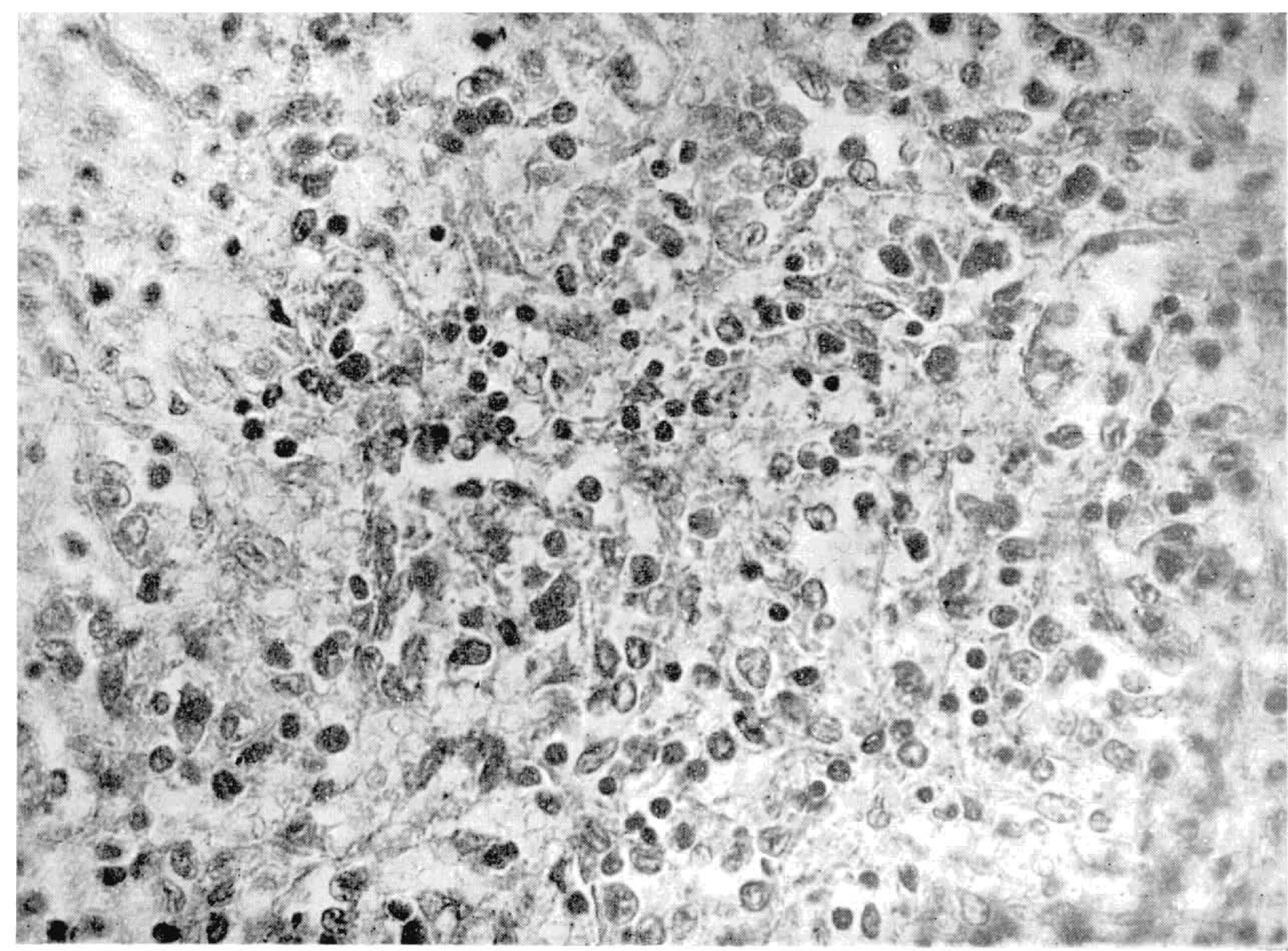

Fig. 4

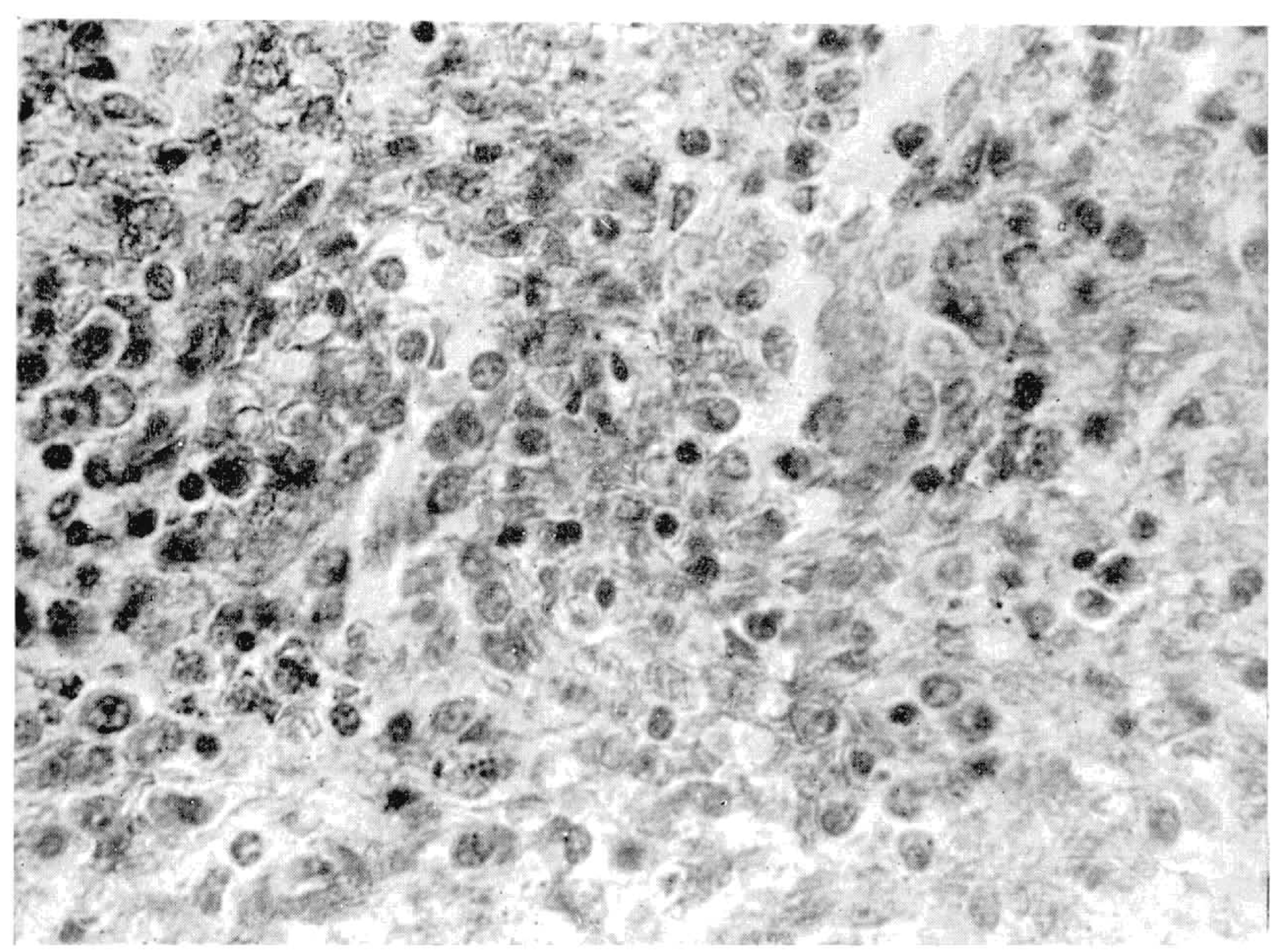

Fig. 6

Fotomicro de J. PINTO

W. O. Cruz: Metaplasia mieloide do baço na ancilostomose.

Myeloide Metaplasia of Spleen in Hookworm disease. 

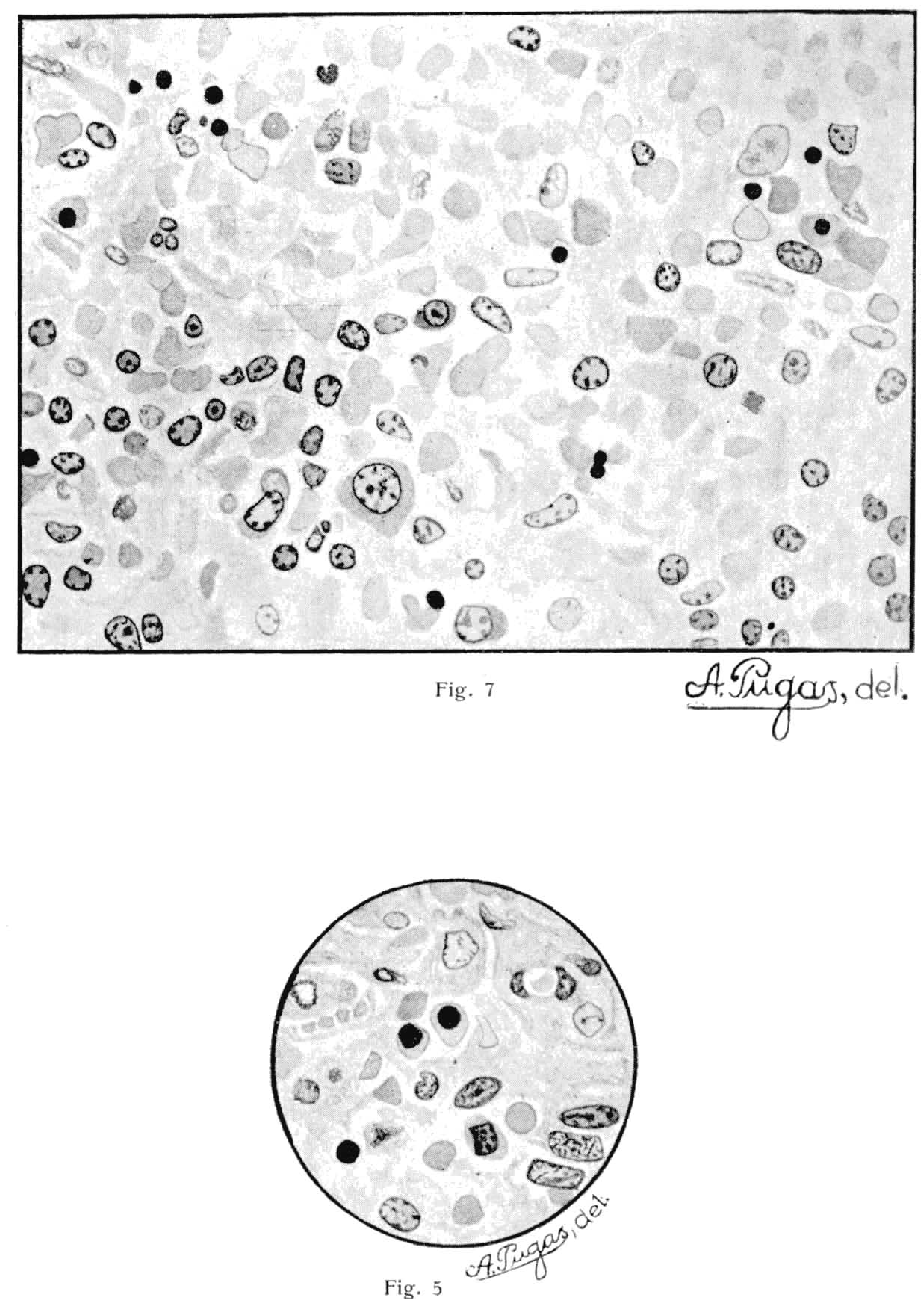

W. 0. Cruz : Metaplasia mieloide do baço na ancilostomose. Myeloide Metaplasia of Spleen in Hookworm disease. 